\title{
Reference intervals of gestational sac, yolk sac, embryonic length, embryonic heart rate at 6-10 weeks after in vitro fertilization-embryo transfer
}

Yan Ouyang ${ }^{1,2,3}$, Jiabi Qin ${ }^{4}$, Ge Lin ${ }^{2,3}$, Shuanglin Xiang ${ }^{1}$ and Xihong $\mathrm{Li}^{2,3^{*}}$ (I)

\begin{abstract}
Background: Accurately determining the normal range of early pregnancy markers can help to predict adverse pregnancy outcomes. The variance in ovulation days leads to uncertain accuracy of reference intervals for natural pregnancies. While the gestational age (GA) is accurate estimation during in vitro fertilization-embryo transfer (IVFET). Thus, the objective of this research is to construct reference intervals for gestational sac diameter (GSD), yolk sac diameter (YSD), embryonic length (or crown-rump length, CRL) and embryonic heart rate (HR) at 6-10 gestational weeks (GW) after IVF-ET.
\end{abstract}

Methods: From January 2010 to December 2016, 30,416 eligible singleton pregnancies were retrospectively recruited. All included participants had full records of early ultrasound measurements and phenotypically normal live neonates after $37 \mathrm{GW}$, with birth weights > the 5th percentile for gestational age. The curve-fitting method was used to screen the optimal models to predict GSD, CRL, YSD and HR based on gestational days (GD) and GW. Additionally, the percentile method was used to calculate the 5th, 50th, and 95th percentiles.

Results: There were significant associations among GSD, CRL, YSD, HR and GD and GW, the models were GSD =$29.180+1.070 \mathrm{GD}$ (coefficient of determination $\left.\left[R^{2}\right]=0.796\right), C R L=-11.960-0.147 \mathrm{GD}+0.011 \mathrm{GD}^{2}\left(\mathrm{R}^{2}=0.976\right), \mathrm{YSD}=-$ $2.304+0.184 G D-0.011 G D^{2}\left(R^{2}=0.500\right), H R=-350.410+15.398 G D-0.112 G^{2}\left(R^{2}=0.911\right)$; and $G S D=-29.180+7.492$ $\mathrm{GW}\left(\mathrm{R}^{2}=0.796\right), \mathrm{CRL}=-11.960-1.028 \mathrm{GW}+0.535 \mathrm{GW}^{2}\left(\mathrm{R}^{2}=0.976\right), \mathrm{YSD}=-2.304+1.288 \mathrm{GW}-0.054 \mathrm{GW}^{2}\left(\mathrm{R}^{2}=0.500\right)$, $\mathrm{HR}=-350.410+107.788 \mathrm{GW}-5.488 \mathrm{GW}^{2}\left(\mathrm{R}^{2}=0.911\right),(p<0.001)$.

Conclusions: Reference intervals for GSD, YSD, HR and CRL at 6-10 gestational weeks after IVF-ET were established.

Keywords: Reference interval, Crown-rump length, Embryonic heart rate, Gestational sac, Yolk sac, In vitro fertilizationembryo transfer, First trimester

\footnotetext{
* Correspondence: xihongliyxk@163.com

${ }^{2}$ Reproductive and Genetic Hospital of CITIC-Xiangya, Changsha, China

${ }^{3}$ Clinical Research Center For Reproduction and Genetics in Hunan Province, Changsha, China

Full list of author information is available at the end of the article
}

(c) The Author(s). 2020 Open Access This article is licensed under a Creative Commons Attribution 4.0 International License, which permits use, sharing, adaptation, distribution and reproduction in any medium or format, as long as you give appropriate credit to the original author(s) and the source, provide a link to the Creative Commons licence, and indicate if changes were made. The images or other third party material in this article are included in the article's Creative Commons licence, unless indicated otherwise in a credit line to the material. If material is not included in the article's Creative Commons licence and your intended use is not permitted by statutory regulation or exceeds the permitted use, you will need to obtain permission directly from the copyright holder. To view a copy of this licence, visit http://creativecommons.org/licenses/by/4.0/. The Creative Commons Public Domain Dedication waiver (http://creativecommons.org/publicdomain/zero/1.0/) applies to the data made available in this article, unless otherwise stated in a credit line to the data. 


\section{Background}

Accurately determining the normal range of early pregnancy markers can help to predict adverse pregnancy outcomes, such as miscarriage. It is also useful to determine the number of foetuses and their viability, type of twinning, and presence of gross fetal abnormalities, placental problems, and uterine or adnexal problems. Some studies have constructed reference intervals that mostly depend on natural conceptions of women with regular menstrual cycles and known dates of their last menstrual periods (LMPs) [1-3]. However, a discrepancy of more than 7 days in gestation calculated by menstrual history and by ultrasound was found in approximately 15\% of women with regular menstrual cycles and specific LMP dates due to the variance in ovulation days [4]. Thus, ultrasound measurements of embryonic and foetal crown-rump length (CRL) are useful to estimate gestational age (GA) in early pregnancy $[5,6]$, and the classic Robinson curve is the most common method [7]. However, some researchers have shown that there is generalized underestimation of GA by the Robinson curve $[8,9]$. These findings have led to uncertain accuracy of reference intervals for natural pregnancies.

During in vitro fertilization-embryo transfer (IVF-ET), the day of oocyte retrieval and ET are known; thus, the GA estimation is accurate. We speculate that reference intervals derived from IVF-ET data are more accurate than those derived from natural conception and be more suitable for IVF populations. With the rapid development of artificial reproductive technology, especially after the implementation of the two-child policy in mainland China, more infertile couples conceive with this treatment $[10,11]$. However, there is no research focused on constructing reference intervals for 4 ultrasound indicators of early pregnancy following IVF-ET or specifically targeting the Chinese population.

This study analysed data from a large cohort of 30,416 singleton pregnancies with normal outcomes from a Chinese population, aiming to construct reference intervals for gestational sac diameter (GSD), yolk sac diameter (YSD), heart rate (HR) and CRL at 6-10 gestational weeks (GW) following IVF-ET. The optimal models for predicting GSD, CRL, YSD and HR based on GA were also analysed.

\section{Methods}

\section{Patients}

The institutional review board approved this study before data collection (LL-SC-2019-015). The study was conducted using anonimized dataset of patients for research purposes and that it was conducted in agreement with Helsinki declaration for research ethics. STROBE Guidelines were followed for reporting this observational study [12]. This retrospective study was involved 30,416 singleton pregnancies following IVF-ET at the Reproductive and Genetic Hospital of CITIC Xiangya from January 2010 to December 2016 (Changsha, China, Fig. 1). In order to create models that are applicable to more patients, the study population was minimally selected. The age of women in the studied population was up to 45 years. Due to the retrospective nature of this study, informed consent was waived. The kinds of insemination methods included IVF, intracytoplasmic sperm injection (ICSI),

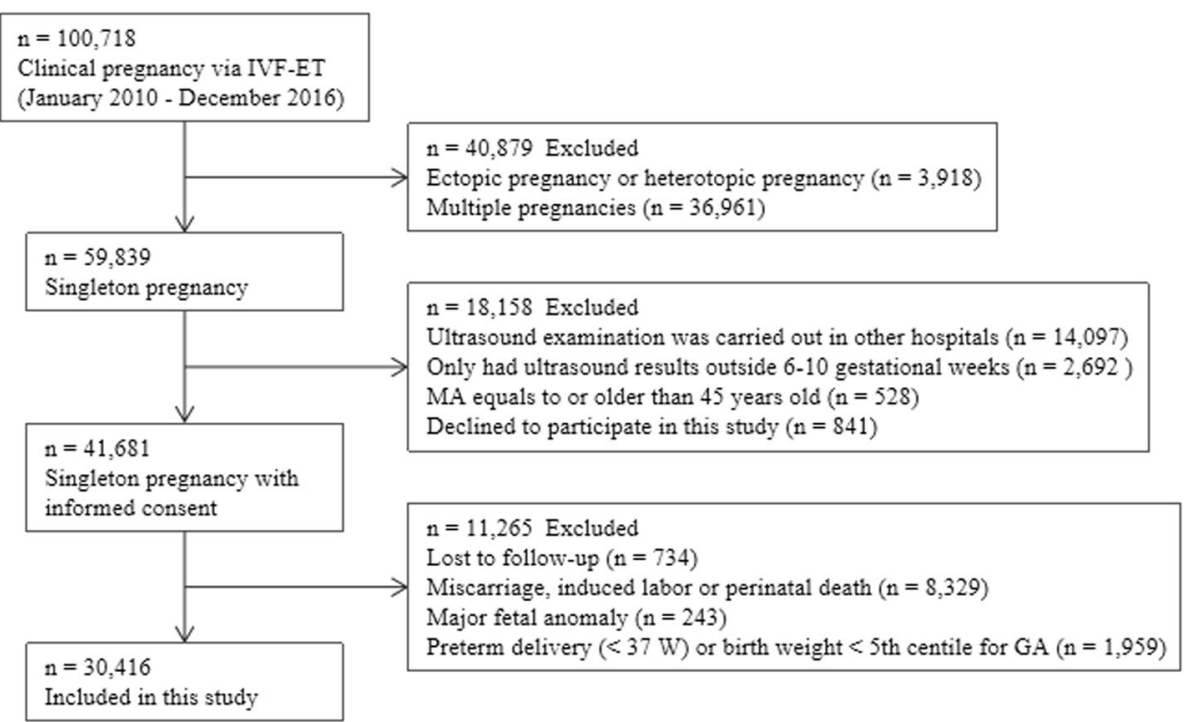

Fig. 1 Flow chart of patient inclusion. IVF-ET, in vitro fertilization-embryo transfer; MA, maternal age; GA, gestational age 
IVF/ICSI, and preimplantation genetic diagnosis (PGD). In these patients, 1-3 fresh or frozen embryos with good quality were transferred at the day-3 or day- 5 stage, and the embryo scoring method was described in our previous studies [13, 14]. Serumhuman chorionic gonadotropin (hCG) levels were measured on day 14 (blastocysts on day 12), and transvaginal scans were usually performed in the first trimester to confirm clinical pregnancy.

Pregnancy and perinatal outcomes were tracked by a specified team via telephone call or fax at our centre. The inclusion criteria were as follows: (1) live singleton pregnancy following IVF-ET; (2) embryonic GSD, YSD, HR were fully measured and recorded at 6-10 GW; and (3) live birth after $37 \mathrm{GW}$ of a phenotypically normal neonate with a birth weight $>$ 5th percentile for GA [15]. All enrolled women were informed the possibility of using their ultrasound records from the first trimester to construct reference intervals before ultrasound examinations were performed.

\section{Ultrasound measurements}

We collected the first ultrasound examination results from each patient during 6-10 GW. The ultrasound scans were performed by 4 experienced sonographers with a GE VOLUSON E8/730 (General Electric Tech Co., Ltd., New York, USA) equipped with a $5-9 \mathrm{MHz}$ transvaginal probe. The measurements referred to the ISUOG practice guidelines [16] and conformed to uniform standards: GSD was calculated the mean value of 3 perpendicular diameters with the callipers placed at the inner edges of the trophoblast; YSD was calculated as the average of 3 perpendicular diameters with the callipers placed at the centre of the yolk sac (YS) wall; CRL was measured as the greatest length of the embryo in the anterior to posterior dimension; and HR was calculated from frozen M-mode images with electronic callipers by measuring the distance between two heart waves.

Intra- and interobserver reliability of measurements was tested on a random selection of 30 pregnancies at day 28 after ET. Each observer performed two measurements of GSD, YSD, CRL and HR on separate occasions and was unaware of others' results. Written informed consent was obtained from all test patients before ultrasound scanning. The reference intervals were analysed according to the gestational days (GD) and GW. The GD can be deduced by adding 17 to the day of ET for cleavage stage embryos or adding 19 for blastocysts (Day 5 or Day 6), and the corresponding GW was obtained by dividing the GD by 7 [14]. The calculation method of fresh embryo and frozen embryo was the same.

\section{Statistical analysis}

All statistical analyses were performed using SPSS software version 17.0 (SPSS, Inc., Chicago, IL, USA). Measurements are presented as the mean \pm standard deviation (SD), and the enumerated data are expressed as numbers (percentages). The curve-fitting method was used to screen the optimal models for predicting GSD, CRL, YSD and HR based on GD and GW. We determined the optimal model based on the size of coefficient of determination $\left(R^{2}\right)$. The model with the largest $R^{2}$ was ultimately selected as the best model. Additionally, the percentile method was used to calculate the 5th, 50th, and 95th percentiles for each time point. Scatter plots of GSD, CRL, YSD and HR compared with

Table 1 Clinical characteristics of the study population

\begin{tabular}{|c|c|}
\hline Parameter & Value \\
\hline Patients (n) & 30,416 \\
\hline Age (years) & $30.4 \pm 4.4$ \\
\hline BMI $\left(\mathrm{kg} / \mathrm{m}^{2}\right)$ & $21.8 \pm 2.8$ \\
\hline Infertility duration (years) & $4.8 \pm 3.4$ \\
\hline Transfer cycle (n) & $1.2 \pm 0.6$ \\
\hline \multicolumn{2}{|l|}{ Infertility type } \\
\hline Primary & $13,971(45.9 \%)$ \\
\hline Secondary & $16,445(54.1 \%)$ \\
\hline \multicolumn{2}{|l|}{ Cause of infertility } \\
\hline Male & $2513(8.3 \%)$ \\
\hline Female & $17,946(59.0 \%)$ \\
\hline Combined female and male factors & 8859 (29.1\%) \\
\hline Unexplained & $1098(3.6 \%)$ \\
\hline \multicolumn{2}{|l|}{ Insemination methods } \\
\hline IVF & $14,445(47.5 \%)$ \\
\hline$|\mathrm{CS}|$ & $5723(18.8 \%)$ \\
\hline IVF/ICSI & $10,213(33.6 \%)$ \\
\hline PGD & $35(0.1 \%)$ \\
\hline \multicolumn{2}{|l|}{ Embryo type } \\
\hline Fresh & $20,168(66.3 \%)$ \\
\hline Frozen & $10,248(33.7 \%)$ \\
\hline \multicolumn{2}{|l|}{ Mode of delivery } \\
\hline Spontaneous delivery & $8165(26.8 \%)$ \\
\hline Caesarean section & $22,251(73.2 \%)$ \\
\hline Birth weight (g) & $3350.0 \pm 240.0$ \\
\hline 5th centile & 2550.0 \\
\hline 50th centile & 3350.0 \\
\hline 95th centile & 4100.0 \\
\hline
\end{tabular}

Data are presented as $\mathrm{n}(\%)$ or the mean $\pm \mathrm{SD}$

$B M I$ body mass index, IVF in vitro fertilization, ICSI intracytoplasmic sperm injection, IVF/ICSI refers to either IVF or ICSI performed, PGD preimplantation genetic diagnosis (refers to PGT-M) 
GD and GW were obtained. Correlation coefficients were calculated to analyse the intra- and interobserver reliability. A $p$ value $<0.05$ was considered significant.

\section{Results}

From January 2010 to December 2016, 100,718 infertile patients obtained clinical pregnancies via IVF-ET in our hospital. After data exclusion, a total of 30, 416 singleton pregnancies with normal outcomes were included in this study. The clinical characteristics of the study population were shown as Table 1. The measurements of GSD, CRL, YSD, and HR showed significant intra- and inter-observer correlations $(p<0.001)$.

\section{Gestational sac diameter}

There was a significant linear association between GSD and GA. The best fit models were as follows: GSD = $-29.180+1.070 \mathrm{GD}(\mathrm{R} 2=0.796, P<0.001)$ and GSD $=$ $-29.180+7.492$ GW $(\mathrm{R} 2=0.796, P<0.001)$. Figure 2 shows scatter plots with the 5 th, 50th, 95th percentiles of GSD against GD.

\section{Crown-rump length}

There was a significant quadratic association between CRL and GA. The most appropriate fit models were as follows: $\mathrm{CRL}=-11.960-0.147 \mathrm{GD}+0.011 \mathrm{GD}^{2}$ $\left(\mathrm{R}^{2}=0.976, \quad p<0.01\right)$ and $\mathrm{CRL}=-11.960-1.028$ $\mathrm{GW}+0.535 \mathrm{GW}^{2} \quad\left(\mathrm{R}^{2}=0.976, p<0.001\right)$. Figure 3 shows scatter plots with the 5th, 50th, 95th percentiles of CRL versus GD.

\section{Yolk sac diameter}

A significant association between YSD and GA was found. The following quadratic models showed the most appropriate fit: YSD $=-2.304+0.184 \mathrm{GD}-0.011 \mathrm{GD}^{2}$ $\left(\mathrm{R}^{2}=0.500, p<0.01\right)$, and $\mathrm{YSD}=-2.304+1.288 \mathrm{GW}$ $0.054 \mathrm{GW}^{2}\left(\mathrm{R}^{2}=0.500, p<0.001\right)$. Scatter plots with the 5 th, 50th, 95th percentiles of YSD against GD are presented in Fig. 4.

\section{Heart rate}

A significant association between $\mathrm{HR}$ and GA was found. The following quadratic models showed the best fit: $\mathrm{HR}=-350.410+15.398 \mathrm{GD}-0.112 \mathrm{GD}^{2}\left(\mathrm{R}^{2}=0.911\right.$, $p<0.001)$ and $\mathrm{HR}=-350.410+107.788 \mathrm{GW}-5.488$ $\mathrm{GW}^{2}\left(\mathrm{R}^{2}=0.911, p<0.001\right)$. Scatter plots with the 5 th,

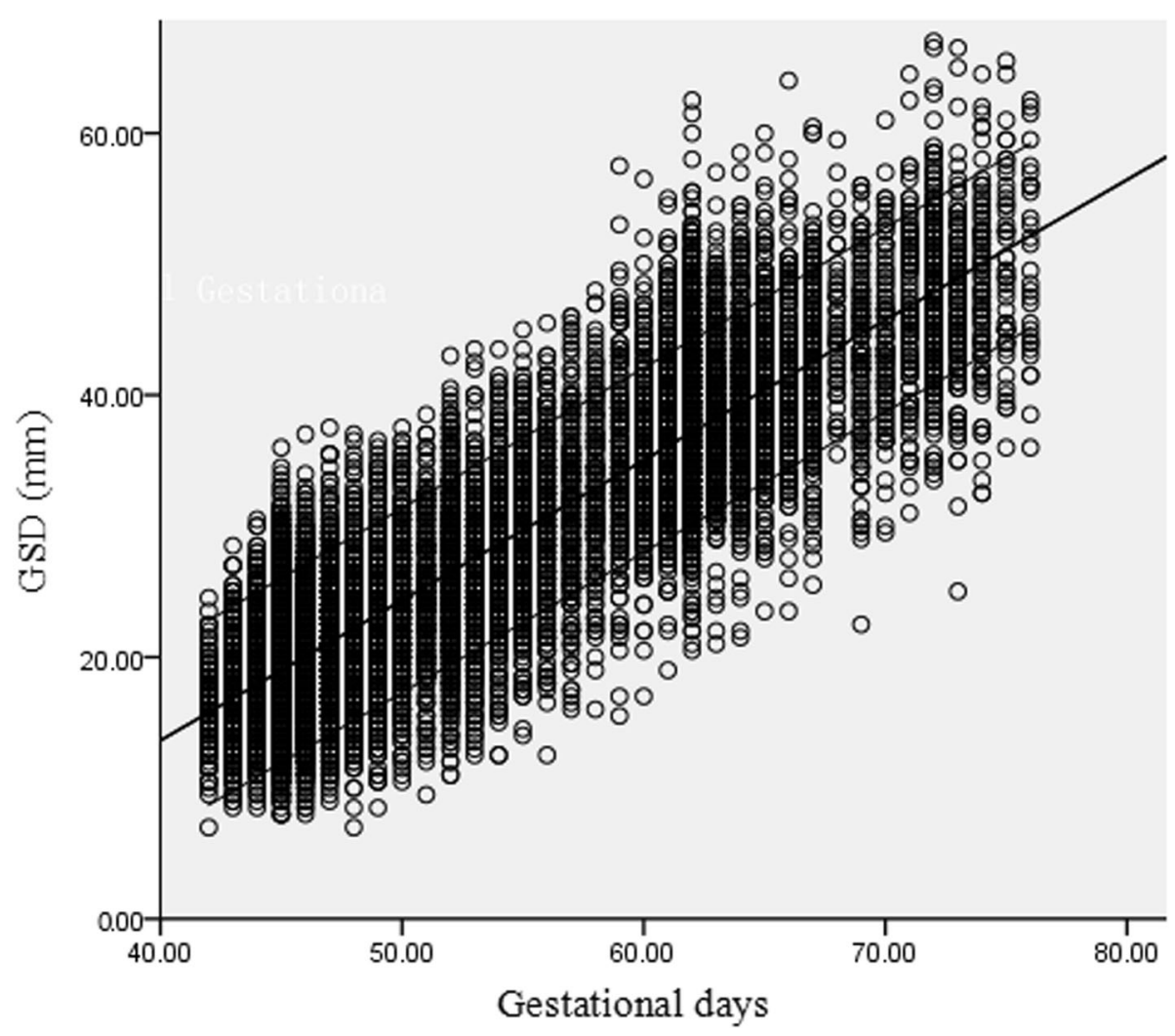

Fig. 2 Scatter plots with the 5th, 50th, 95th percentiles of gestational sac diameter (GSD) against gestational days (GD) 


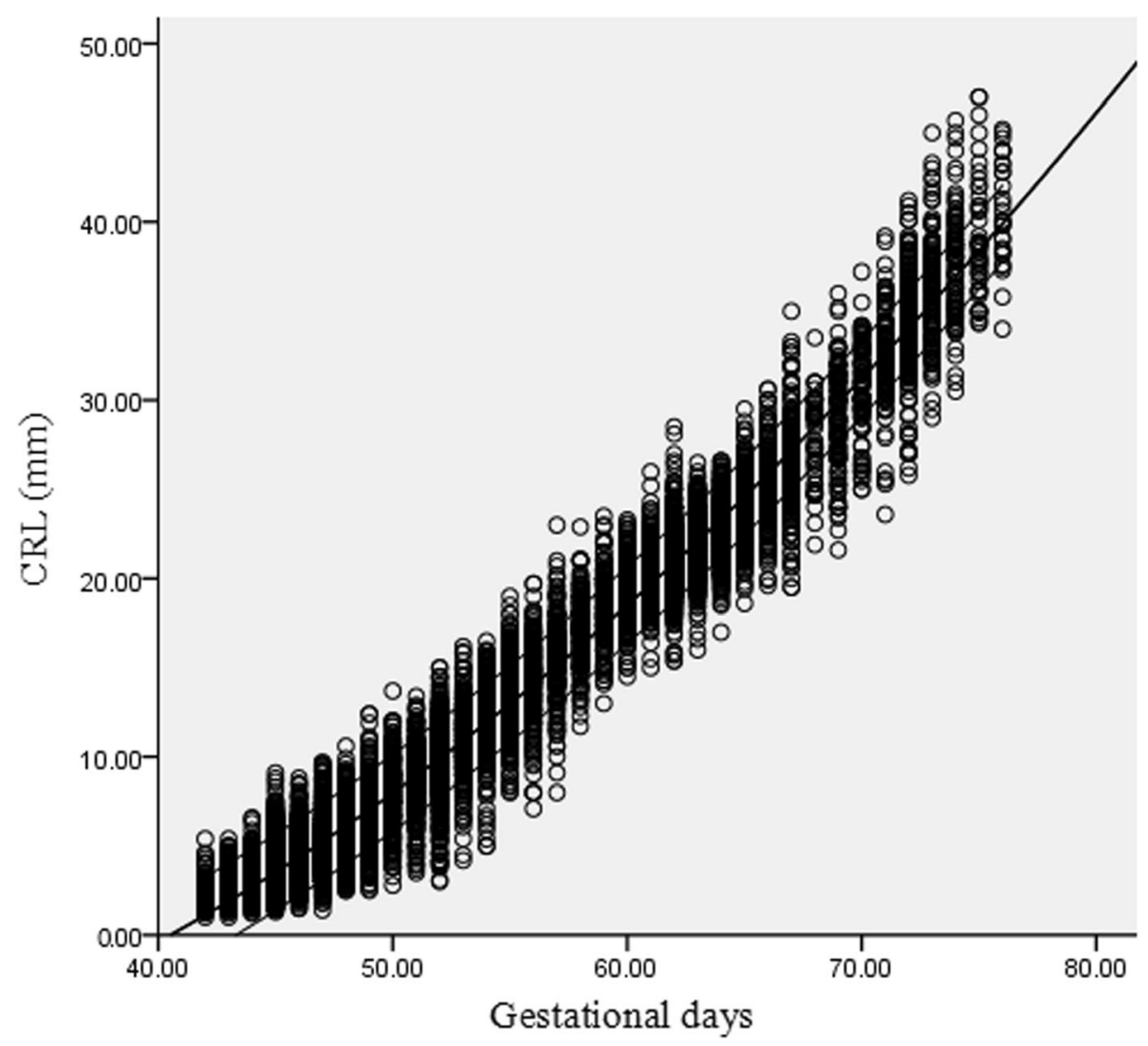

Fig. 3 Scatter plots with the 5th, 50th, 95th percentiles of crown-rump length (CRL) against gestational days (GD)

50th, 95th percentiles of HR against GD are presented in Fig. 5.

Additionally, the details of the reference intervals for GSD, CRL, YSD and HR based on GD and GW are shown in Tables 2 and 3, respectively.

\section{Discussion}

In this study, we constructed reference intervals for GSD, YSD, CRL, and HR at 6-10 GW for an IVF population with a large sample of Chinese women. The optimal models for predicting GSD, CRL, YSD and HR based on GA were also presented.

In this study, a high proportion of CS is noted in Table 1. This high proportion of CS may be due to the high CS rate in China, which was estimated to be approximately $50 \%$ of births $[11,17]$. However, the CS rate was as high as $73.2 \%$ in this study. The babies were conceived via IVF, and the implementation of the two-child policy in China has led to an increase in the number of elderly maternal pregnancies; over half of elderly mothers underwent CS for their first delivery; these factors might have contributed to the high CS rate in the IVF population [11].
Optimal models for predicting GSD, CRL, YSD and HR based on GA were established and showed that GSD linearly increases with GA. CRL, YSD, and HR had significant quadratic associations with GA. These models can be conveniently used in clinical practice to calculate the corresponding values of GSD, CRL, YSD and HR according to GA. However, the YSD models showed relatively lower $\mathrm{R}^{2}(0.500$ for both GD and $\mathrm{GW}$ ) than the other models, suggesting that the prediction models can only explain $50 \%$ of the changes in YSD; thus, in addition to GA, there are other factors to be explored.

The reference intervals for GSD, YSD, HR and CRL at 6-10 GW were constructed from a large sample in this study. This data can provide clinicians a reliable reference to analyse the development of early embryos after IVF-ET and facilitate monitoring of pregnancy outcomes at an early stage. GSD, YSD and CRL were found to gradually increase from 6 to $10 \mathrm{GW}$. However, HR increased from $6 \mathrm{GW}$, reaching a peak at $9 \mathrm{GW}(176.0$ $\mathrm{bpm})$ and decreasing from there. This trend in HR was consistent with the results of previous studies $[18,19]$ and may be due to the development of the embryonic heart and its conductive system [20]. 


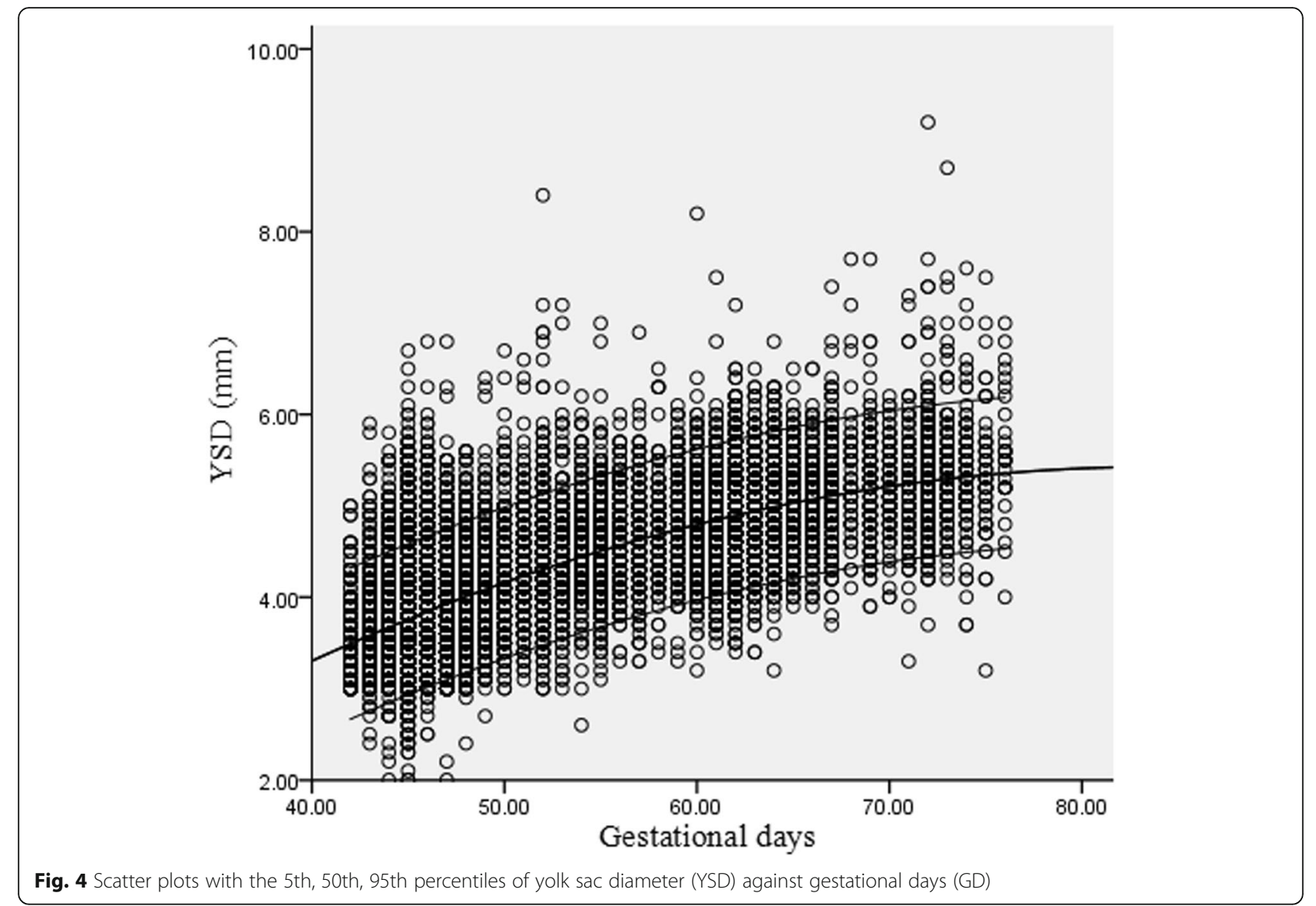

For comparison with previous studies, we performed a literature search of PubMed, and representative literature is listed in Table 4 [2, 5, 7, 21-26]. Most previous studies were conducted between the 1990s and 2000s and had small sample sizes of subjects with spontaneous conception or a mixed population. The most obvious difference between our study and previous studies was the CRL at early GA. In the studies by Grisolia et al. [22] and McLennan et al. [26], the CRL at day 45 was $7 \mathrm{~mm}$; however, the CRL was $3.4 \mathrm{~mm}$ in our study. Both these studies used dating models among spontaneous conception or mixed populations to calculate GA according to CRL. Some researchers have suggested that the use of assisted reproduction data can improve dating accuracy; however, the accuracy is limited before 7 GW and is equivocal for menstrual dating beyond that GA [26], which may partly explain the considerable differences in CRL at day 45 between our study and previous studies. Additionally, CRL has been reported to overestimate gestation [27], and using CRL to determine GA has been reported to be less accurate than GA estimated by a certain LMP or day of oocyte retrieval in early pregnancy [28]; therefore, the CRL corresponding to the calculated GA is longer than the CRL of the same GA in IVF populations.

The most popular formula for pregnancy dating originated from the study by Robinson and Fleming [7], and several studies proposing different dating equations have been reported since then. The use of different formulas can lead to discrepancies in GA estimation and corresponding differences in GSD, CRL, YSD and HR. In addition, different measurement methods may also lead to differences in ultrasound indicators. For example, when measuring YSD, some researchers prefer to place the calliper on the outside limits of the YS wall [29], while some place the calliper on the inner limits of the YS wall [30]. The measurements made in the study by Robinson and Fleming [7] were measured transabdominally, which might not be the same as measurements obtained transvaginally. Furthermore, the values in some articles were presented as means [23-25], while they were reported as medians in other studies [5, 22], which may also partly cause these differences.

Our study has several strengths. The large sample size allowed us to establish special reference 


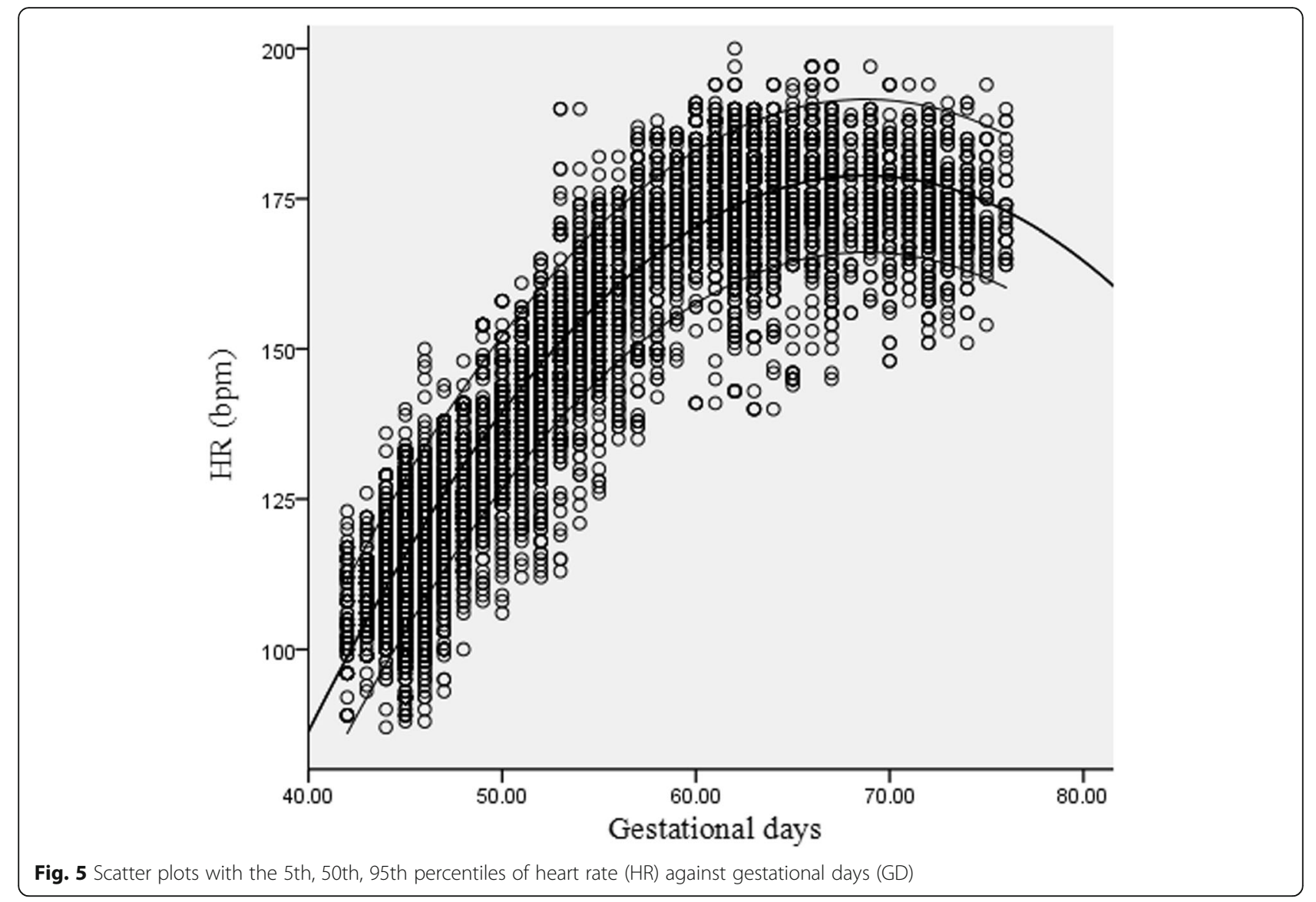

intervals and construct optimal models for GSD, CRL, YSD and HR for IVF populations, which may be helpful for accurately analysing and monitoring the development of early pregnancy following IVFET. However, one potential weakness was that all the data were confined to one reproductive centre; although it is the largest centre in China, territorial limitations exist. Future studies with multi-centre samples are necessary to establish nationwide or worldwide references. Secondly, although the total sample was quite large, the patients were unevenly distributed. Most patients underwent their first ultrasound on day 28 after ET ( $45 \mathrm{GD}, n=12,687$ ); however, much fewer patients underwent ultrasound on other days, particularly on later days. However, it is impractical to perform ultrasound for each patient every day to evenly distribute the sample. Therefore, future studies are needed to verify our reference intervals. Thirdly, to compare normal data with abnormal outcomes and try to understand whether the measurements may be somehow function as prognostic factors for abnormalities would be an interesting future work. Fourthly, since we collected the data retrospectively from the hospital database, some baseline data such as pharmacological treatments uses, parity, significant maternal diseases and smoking status were missing.

In addition, only fresh embryos, frozen embryos and days of transplantation were recorded for transplantation, but not blastocyst transplantation, so we were unable to further analyze the results of blastocyst transplantation. Previous studies have found lower uterine artery pulsatility index, proportion of small-for-gestational-age (SGA) [31] decreased risks of preterm \birth and low birth weight babies but a higher risk of large for GA babies as well as hypertensive disorders of pregnancies associated with pregnancies conceived from frozen embryos compared to fresh transfer [32]. While the difference between fresh and frozen embryos needs to be further confirmed by our follow-up studies. Another potential weakness was that IVF pregnancy may not be biologically equivalent to spontaneous conception due to increased risks of obstetrics and perinatal complications were shown for IVF pregnancies [3335]. Thus, whether references based on IVF population are suitable for natural conceptions needs further elucidation. 
Table 2 Reference intervals for GSD, YSD, CRL and HR based on GD

\begin{tabular}{|c|c|c|c|c|c|c|c|c|c|c|c|c|c|}
\hline \multirow{2}{*}{$\begin{array}{l}\text { Gestational } \\
\text { days }\end{array}$} & \multirow[t]{2}{*}{$\mathrm{n}$} & \multicolumn{3}{|c|}{ GSD (mm) } & \multicolumn{3}{|c|}{ CRL (mm) } & \multicolumn{3}{|c|}{ YSD (mm) } & \multicolumn{3}{|c|}{ HR (bpm) } \\
\hline & & 5 th & 50th & 95th & 5th & 50th & 95 th & 5th & 50th & 95 th & 5th & 50th & 95th \\
\hline 42 & 159 & 11.5 & 16.0 & 21.5 & 1.5 & 2.2 & 4.0 & 3.0 & 3.6 & 4.5 & 96.0 & 108.0 & 117.0 \\
\hline 43 & 503 & 12.0 & 17.0 & 23.5 & 1.8 & 2.6 & 4.1 & 3.0 & 3.6 & 4.6 & 101.2 & 109.0 & 115.0 \\
\hline 44 & 2077 & 13.5 & 18.0 & 24.0 & 2.0 & 3.0 & 4.3 & 3.0 & 3.6 & 4.6 & 104.0 & 112.0 & 121.0 \\
\hline 45 & 12,687 & 14.0 & 19.0 & 25.0 & 2.4 & 3.4 & 4.9 & 3.1 & 3.7 & 4.6 & 103.0 & 117.0 & 128.0 \\
\hline 46 & 2726 & 14.0 & 19.5 & 26.0 & 2.6 & 3.9 & 5.7 & 3.1 & 3.8 & 4.7 & 103.0 & 118.0 & 129.0 \\
\hline 47 & 1472 & 14.5 & 21.0 & 28.0 & 3.0 & 4.8 & 7.2 & 3.1 & 3.9 & 4.9 & 112.0 & 122.0 & 135.0 \\
\hline 48 & 648 & 14.5 & 21.5 & 29.0 & 3.4 & 5.6 & 8.1 & 3.2 & 4.0 & 5.0 & 114.0 & 124.0 & 140.0 \\
\hline 49 & 389 & 13.8 & 22.5 & 31.8 & 3.9 & 6.7 & 9.5 & 3.3 & 4.1 & 5.0 & 120.0 & 132.0 & 148.0 \\
\hline 50 & 366 & 15.0 & 23.5 & 33.5 & 4.7 & 8.0 & 10.8 & 3.4 & 4.2 & 5.3 & 122.0 & 135.0 & 150.0 \\
\hline 51 & 326 & 15.9 & 24.5 & 32.8 & 5.4 & 8.9 & 11.8 & 3.6 & 4.3 & 5.3 & 121.0 & 140.0 & 154.0 \\
\hline 52 & 760 & 17.0 & 26.0 & 35.5 & 6.1 & 10.1 & 12.6 & 3.6 & 4.3 & 5.3 & 128.1 & 147.0 & 158.0 \\
\hline 53 & 321 & 16.6 & 26.0 & 35.0 & 8.0 & 10.8 & 13.7 & 3.6 & 4.4 & 5.5 & 134.0 & 149.0 & 168.6 \\
\hline 54 & 328 & 18.5 & 28.0 & 37.5 & 9.0 & 12.4 & 15.2 & 3.9 & 4.5 & 5.4 & 136.9 & 154.0 & 169.0 \\
\hline 55 & 479 & 21.0 & 29.0 & 37.5 & 10.2 & 13.6 & 16.4 & 3.8 & 4.5 & 5.4 & 145.0 & 159.0 & 173.0 \\
\hline 56 & 269 & 20.5 & 30.5 & 39.5 & 10.5 & 14.6 & 17.2 & 3.9 & 4.6 & 5.4 & 142.5 & 162.0 & 174.0 \\
\hline 57 & 280 & 21.5 & 31.5 & 41.5 & 11.9 & 15.8 & 19.0 & 3.8 & 4.6 & 5.5 & 148.0 & 167.0 & 181.9 \\
\hline 58 & 199 & 23.0 & 33.0 & 42.5 & 13.9 & 17.1 & 20.1 & 4.0 & 4.6 & 5.5 & 149.0 & 170.0 & 185.0 \\
\hline 59 & 230 & 24.5 & 34.0 & 45.7 & 15.1 & 18.3 & 21.0 & 4.0 & 4.8 & 5.7 & 160.0 & 174.0 & 185.0 \\
\hline 60 & 321 & 28.1 & 35.5 & 44.5 & 16.7 & 19.1 & 21.6 & 4.0 & 4.7 & 5.7 & 162.2 & 174.0 & 188.0 \\
\hline 61 & 563 & 29.5 & 36.5 & 46.5 & 18.0 & 20.2 & 22.4 & 4.0 & 4.8 & 5.6 & 167.0 & 176.0 & 188.0 \\
\hline 62 & 2247 & 30.5 & 37.5 & 47.3 & 19.0 & 21.0 & 23.2 & 4.2 & 4.8 & 5.6 & 160.0 & 176.0 & 188.0 \\
\hline 63 & 662 & 31.0 & 38.0 & 47.5 & 19.5 & 21.8 & 24.4 & 4.1 & 4.9 & 5.7 & 161.2 & 176.0 & 188.0 \\
\hline 64 & 583 & 31.5 & 39.0 & 48.9 & 20.3 & 23.0 & 25.3 & 4.2 & 5.0 & 5.8 & 164.0 & 178.0 & 188.0 \\
\hline 65 & 319 & 32.0 & 40.0 & 50.5 & 21.0 & 24.0 & 26.9 & 4.2 & 5.0 & 5.8 & 164.0 & 176.0 & 186.0 \\
\hline 66 & 207 & 32.5 & 40.0 & 50.5 & 21.7 & 25.0 & 28.8 & 4.2 & 5.1 & 5.9 & 164.0 & 178.0 & 190.6 \\
\hline 67 & 282 & 33.6 & 42.5 & 51.0 & 22.5 & 26.5 & 30.8 & 4.4 & 5.2 & 6.0 & 158.2 & 176.0 & 190.0 \\
\hline 68 & 57 & 37.5 & 44.5 & 55.2 & 23.9 & 28.9 & 31.0 & 4.3 & 5.2 & 6.8 & 161.4 & 174.0 & 188.0 \\
\hline 69 & 157 & 31.4 & 43.5 & 53.0 & 24.0 & 29.1 & 33.0 & 4.3 & 5.2 & 6.1 & 166.9 & 176.0 & 189.1 \\
\hline 70 & 106 & 35.9 & 43.5 & 54.5 & 26.0 & 31.0 & 34.1 & 4.4 & 5.1 & 6.0 & 156.4 & 176.0 & 186.7 \\
\hline 71 & 121 & 35.1 & 46.0 & 56.4 & 27.9 & 32.3 & 36.4 & 4.3 & 5.2 & 6.2 & 164.0 & 175.0 & 188.0 \\
\hline 72 & 255 & 38.4 & 47.0 & 57.0 & 29.2 & 34.3 & 38.4 & 4.4 & 5.2 & 6.2 & 158.0 & 174.0 & 186.0 \\
\hline 73 & 132 & 37.0 & 46.0 & 56.2 & 31.6 & 36.4 & 41.7 & 4.5 & 5.4 & 6.7 & 159.7 & 174.0 & 186.7 \\
\hline 74 & 104 & 37.0 & 48.0 & 60.3 & 33.1 & 38.0 & 42.9 & 4.2 & 5.3 & 6.5 & 160.0 & 173.5 & 185.0 \\
\hline 75 & 51 & 39.0 & 49.0 & 62.4 & 34.5 & 38.3 & 46.4 & 4.2 & 5.3 & 6.9 & 162.6 & 171.0 & 186.2 \\
\hline 76 & 30 & 37.4 & 49.0 & 62.2 & 35.0 & 40.1 & 45.1 & 4.3 & 5.5 & 6.9 & 164.0 & 172.0 & 188.9 \\
\hline
\end{tabular}

Table 3 Reference intervals for GSD, YSD, CRL and HR based on GW

\begin{tabular}{|c|c|c|c|c|c|c|c|c|c|c|c|c|c|}
\hline \multirow{2}{*}{$\begin{array}{l}\text { Gestational } \\
\text { weeks }\end{array}$} & \multirow[t]{2}{*}{$n$} & \multicolumn{3}{|c|}{ GSD (mm) } & \multicolumn{3}{|c|}{$\mathrm{CRL}(\mathrm{mm})$} & \multicolumn{3}{|c|}{$\mathrm{YSD}(\mathrm{mm})$} & \multicolumn{3}{|c|}{$\mathrm{HR}$ (bpm) } \\
\hline & & 5 th & 50th & 95th & 5 th & 50th & 95th & 5 th & 50th & 95th & 5 th & 50th & 95th \\
\hline 6 & 20,272 & 14.0 & 19.0 & 25.5 & 2.3 & 3.5 & 5.7 & 3.1 & 3.7 & 4.7 & 103.0 & 117.0 & 128.0 \\
\hline 7 & 2969 & 16.5 & 26.0 & 35.5 & 5.3 & 10.1 & 14.8 & 3.5 & 4.3 & 5.3 & 124.0 & 146.0 & 164.5 \\
\hline 8 & 4109 & 26.5 & 36.0 & 46.0 & 14.4 & 20.2 & 22.8 & 4.1 & 4.8 & 5.6 & 158.0 & 174.0 & 186.0 \\
\hline 9 & 2267 & 31.5 & 40.0 & 50.0 & 20.2 & 23.4 & 29.8 & 4.2 & 5.0 & 5.8 & 162.4 & 176.0 & 188.0 \\
\hline 10 & 799 & 37.0 & 46.5 & 57.5 & 29.0 & 34.5 & 41.2 & 4.4 & 5.3 & 6.4 & 160.0 & 174.0 & 186.0 \\
\hline
\end{tabular}


Table 4 Reference values for GSD, YSD, CRL and HR in previous studies and the present study

\begin{tabular}{|c|c|c|c|c|c|c|c|c|c|c|c|c|c|c|c|}
\hline \multirow[t]{2}{*}{ Author } & \multirow[t]{2}{*}{ Studied population } & \multirow[t]{2}{*}{ Inclusion criteria } & \multirow[t]{2}{*}{$\begin{array}{l}\text { Scanning } \\
\text { method }\end{array}$} & \multicolumn{12}{|c|}{$\begin{array}{l}\text { Gestational days } \\
455565\end{array}$} \\
\hline & & & & $\begin{array}{l}\text { GSD } \\
\mathrm{mm}\end{array}$ & $\begin{array}{l}\mathrm{CRL} \\
\mathrm{mm}\end{array}$ & $\begin{array}{l}\text { YSD } \\
\mathrm{mm}\end{array}$ & $\begin{array}{l}\mathrm{HR} \\
\mathrm{bpm}\end{array}$ & $\begin{array}{l}\text { GSD } \\
\mathrm{mm}\end{array}$ & $\begin{array}{l}\mathrm{CRL} \\
\mathrm{mm}\end{array}$ & $\begin{array}{l}\text { YSD } \\
\mathrm{mm}\end{array}$ & $\begin{array}{l}\mathrm{HR} \\
\mathrm{bpm}\end{array}$ & $\begin{array}{l}\text { GSD } \\
\mathrm{mm}\end{array}$ & $\begin{array}{l}\text { CRL } \\
\mathrm{mm}\end{array}$ & $\begin{array}{l}\text { YSD } \\
\mathrm{mm}\end{array}$ & $\begin{array}{l}\text { HR } \\
\text { bpm }\end{array}$ \\
\hline $\begin{array}{l}\text { Robinson and Fleming, } \\
1975[7](n=334)\end{array}$ & Spontaneous & $\begin{array}{l}\text { No information } \\
\text { about outcome }\end{array}$ & TA & - & 6.1 & - & - & - & 13.8 & - & - & - & 24.2 & - & - \\
\hline $\begin{array}{l}\text { Lindsay et al., [21] } \\
1992(n=327)\end{array}$ & Spontaneous & $\begin{array}{l}\text { Pregnancy } \\
\text { continued } \geq \mathbf{2 7} \\
\text { weeks }\end{array}$ & TV & - & - & 2.7 & - & - & - & 3.1 & - & - & - & 3.5 & - \\
\hline $\begin{array}{l}\text { Grisolia et al., [22] } \\
1993(n=248)\end{array}$ & Spontaneous & Normal live birth & TV/TA & 14.0 & 7.0 & - & - & 26.0 & 15.0 & - & - & 38.0 & 25.0 & - & - \\
\hline $\begin{array}{l}\text { Britten et al., [23] } \\
1994(n=361)\end{array}$ & $\begin{array}{l}\text { Assisted } \\
\text { reproduction }\end{array}$ & Normal live birth & TV & - & - & - & 123.3 & - & - & - & 163.0 & - & - & - & - \\
\hline $\begin{array}{l}\text { Yapar et al., [24] } \\
1995(n=1331)\end{array}$ & No information & $\begin{array}{l}\text { No information } \\
\text { about outcome }\end{array}$ & TV & - & - & - & 128.2 & - & - & - & 161.6 & - & - & - & 175.1 \\
\hline $\begin{array}{l}\text { Coulam et al. [25] } \\
1996(n=361)\end{array}$ & $\begin{array}{l}\text { Assisted } \\
\text { reproduction }\end{array}$ & Normal live birth & TV & 16.0 & 5.5 & - & 123.0 & 29.0 & 15.3 & - & 163.0 & - & - & - & - \\
\hline $\begin{array}{l}\text { Tannirandorn et al., [2] } \\
2000(n=547)\end{array}$ & Spontaneous & Normal live birth & TV & - & - & - & 147.4 & - & - & - & 163.9 & - & - & - & 172.7 \\
\hline $\begin{array}{l}\text { McLennan et al., }[26] \\
2008(n=396)\end{array}$ & $\begin{array}{l}\text { Mixed } \\
\text { spontaneous } \\
+ \text { assisted }\end{array}$ & $\begin{array}{l}\text { Pregnancy } \\
\text { continued } \geq 20 \\
\text { weeks }\end{array}$ & TV/TA & - & 7.0 & - & - & - & 15.0 & - & - & - & 26.0 & - & - \\
\hline $\begin{array}{l}\text { Papaioannou et al. } \\
2010(n=4698)\end{array}$ & $\begin{array}{l}\text { Mixed (spontaneous } \\
97.9 \%+\text { assisted } \\
2.1 \%)\end{array}$ & Normal live birth & TV & 17.4 & 5.4 & 3.6 & 120.0 & 27.3 & 14.0 & 4.2 & 156.0 & 37.3 & 24.6 & 4.8 & 174.0 \\
\hline $\begin{array}{l}\text { Our study } 9 \\
(n=30,416)\end{array}$ & $\begin{array}{l}\text { Assisted } \\
\text { reproduction }\end{array}$ & Normal live birth & TV & 19.0 & 3.4 & 3.7 & 117.0 & 29.0 & 13.6 & 4.5 & 159.0 & 40.0 & 24.0 & 5.0 & 176.0 \\
\hline
\end{tabular}

GSD gestational sac diamter, $C R L$ crown rump length, YSD yolk sac diameter, $H R$ heart rate, TA, transabdominal, $T V$ transvaginal

\section{Conclusions}

In conclusion, this study involving a large number of normal pregnancies presented the reference intervals for GSD, CRL YSD and HR at 6-10 GW. These data can be used as reliable references for analysing the development of early embryos after IVF-ET and for monitoring pregnancy outcomes at early stages.

\section{Abbreviations}

GA: Gestational age; IVF-ET: In vitro fertilization-embryo transfer; GSD: Gestational sac diameter; YSD: Yolk sac diameter; CRL: Crown-rump length; HR: Heart rate; GW: Gestational week; GD: Gestational day; LMP: Last menstrual period; hCG: Human chorionic gonadotropin; TVS: Transvaginal scan; YS: Yolk sac; SD: Standard deviation; BMI: Body mass index;

CS: Caesarean section; ICSI: Intracytoplasmic sperm injection;

PGD: Preimplantation genetic diagnosis

\section{Acknowledgments}

The authors thank Qingqing Wu and Mingxiang Zheng for assistance in collecting and sorting clinical data.

\section{Authors' contributions}

LXH and OYY undertook project development, data collection and analysis, and manuscript writing and editing. LG and XSL undertook data collection and manuscript writing and editing. QJB performed the statistical analysis and took part in the manuscript editing. All authors read and approved the final version of the manuscript.

\section{Funding}

This work was funded by the China Postdoctoral Science Foundation funded project (No. 2019 M652778), the Natural Science Foundation of Hunan Province,China (No. 2020JJ5992) and the Science and Technology Project of the Health and Family Planning Commission of Hunan Province (No. C20180289). All funders of the study had no role in the study design, data collection, data analysis nor interpretation.
Availability of data and materials

The data analysed during this study are included in the tables in this published article. The datasets used during the current study are available from the corresponding author on reasonable request.

\section{Ethics approval and consent to participate}

This study and data collection were approved by the Ethics Committee of the Reproductive and Genetic Hospital of CITIC-Xiangya (LL-SC-2019-015). The data were extracted from medical records. Due to the retrospective nature of the study, informed consent was waived.

Consent for publication

Not applicable.

\section{Competing interests}

The authors declare that they have no competing interests.

\section{Author details}

${ }^{1}$ College of Life Science, Hunan Normal University, Changsha, China. ${ }^{2}$ Reproductive and Genetic Hospital of CITIC-Xiangya, Changsha, China.

${ }^{3}$ Clinical Research Center For Reproduction and Genetics in Hunan Province, Changsha, China. ${ }^{4}$ Department of Epidemiology and Health Statistics,

Xiangya School of Public Health, Central South University, Changsha, China.

Received: 17 January 2020 Accepted: 17 August 2020

Published online: 14 September 2020

\section{References}

1. Pexsters A, Daemen A, Bottomley C, Van Schoubroeck D, De Catte L, De Moor $B$, et al. New crown-rump length curve based on over 3500 pregnancies. Ultrasound Obstet Gynecol. 2010;35(6):650-5.

2. Tannirandorn Y, Manotaya S, Uerpairojkit B, Tanawattanacharoen S, Wacharaprechanont T, Charoenvidhya D. Reference intervals for first trimester embryonic/fetal heart rate in a Thai population. J Obstet Gynaecol Res. 2000;26(5):367-72. 
3. Bagratee JS, Regan L, Khullar V, Connolly C, Moodley J. Reference intervals of gestational sac, yolk sac and embryo volumes using three-dimensional ultrasound. Ultrasound Obstet Gynecol. 2009;34(5):503-9.

4. Hoffman CS, Messer LC, Mendola P, Savitz DA, Herring AH, Hartmann KE. Comparison of gestational age at birth based on last menstrual period and ultrasound during the first trimester. Paediatr Perinat Epidemiol. 2008;22(6): 587-96

5. Papaioannou Gl, Syngelaki A, Poon LCY, Ross JA, Nicolaides KH. Normal ranges of embryonic length, embryonic heart rate, gestational sac diameter and yolk sac diameter at 6-10 weeks. Fetal Diagn Ther. 2010;28(4):207-19.

6. Sahota DS, Leung TY, Leung TN, Chan OK, Lau TK. Fetal crown-rump length and estimation of gestational age in an ethnic Chinese population. Ultrasound Obstet Gynecol.2009;33(2):157-60.

7. Robinson HP, Fleming JE. A critical evaluation of sonar \&quot;crown-rump length\&quot; measurements. Br J Obstet Gynaecol. 1975;82(9):702-10.

8. MacGregor SN, Tamura RK, Sabbagha RE, Minogue JP, Gibson ME, Hoffman DI. Underestimation of gestational age by conventional crown-rump length dating curves. Obstet Gynecol. 1987;70(3 Pt 1):344-8.

9. Guirgis RR, Alshawaf T, Dave R, Craft IL. Pregnancy: transvaginal crown-rump length measurements of 224 successful pregnancies which resulted from gamete intra-fallopian transfer or in-vitro fertilization. Hum Reprod. 1993; 8(11):1933-7.

10. Yang $X, L i$ Y, Li C, Zhang W. Current overview of pregnancy complications and live-birth outcome of assisted reproductive technology in mainland China. Fertil Steril. 2014;101(2):385-91.

11. Wang $X$, Zhang $X$, Lai $X$. Exploring an optimal risk adjustment model for public reporting of cesarean section surgical site infections. J Infect Public Health. 2018;11(6):821-25.

12. Cuschieri S. The STROBE guidelines. Saudi J Anaesth. 2019;13(Suppl 1):S31S34.

13. Yi Y, Li X, Ouyang Y, Lin G, Lu G, Gong F. Discriminant analysis forecasting model of first trimester pregnancy outcomes developed by following 9,963 infertile patients after in vitro fertilization. Fertil Steril. 2016;105(5):1261-65.

14. Li X, Ouyang Y, Yi Y, Lin G, Lu G, Gong F. Pregnancy outcomes of women with a congenital unicornuate uterus after IVF-embryo transfer. Reprod BioMed Online. 2017;35:583-91.

15. Poon LCY, Karagiannis G, Staboulidou I, Shafiei A, Nicolaides KH. Reference range of birth weight with gestation and first-trimester prediction of smallfor-gestation neonates. Prenat Diagn. 2011;31(1):58-65.

16. ISUOG practice guidelines: Performance of first-trimester fetal ultrasound scan. Ultrasound Obstetrics Gynecol. 2013;41(1):102-13.

17. Liu Y, Li G, Chen Y, Wang X, Ruan Y, Zou L, et al. A descriptive analysis of the indications for caesarean section in mainland China. BMC Pregnancy Childbirth. 2014;14:410.

18. Stefos TI, Lolis DE, Sotiriadis AJ, Ziakas GV. Embryonic heart rate in early pregnancy. J Clin Ultrasound. 1998;26(1):33-6.

19. Hanprasertpong $T$, Phupong V. First trimester embryonic/fetal heart rate in normal pregnant women. Arch Gynecol Obstet. 2006;274(5):257-60.

20. Merchiers EH, Dhont M, De Sutter PA, Beghin CJ, Vandekerckhove DA. Predictive value of early embryonic cardiac activity for pregnancy outcome. Am J Obs Gynecol. 1991;165(1):11-4.

21. Lindsay DJ, Lovett IS, Lyons EA, Levi CS, Zheng XH, Holt SC, et al. Yolk saC diameter and shape at endovaginal US: predictors of pregnancy outcome in the first trimester. Obstet Gynecol Surv. 1992;183(1):115-8.

22. Grisolia G, Milano K, Pilu G, Banzi C, David C, Gabrielli S, et al. Biometry of early pregnancy with transvaginal sonography. Ultrasound Obstet Gynecol. 1993;3(6):403-11.

23. Britten S, Soenksen DM, Bustillo M, Coulam CB. Pregnancy: very early (24-56 days from last menstrual period) embryonic heart rate in normal pregnancies. Hum Reprod. 1994;9(12):2424-6.

24. Yapar EG, Ekici E, Gökmen O. First trimester fetal heart rate measurements by transvaginal ultrasound combined with pulsed Doppler: an evaluation of 1331 cases. Eur J Obstet Gynecol Reprod Biol. 1995;60(2):133-7.

25. Coulam CB, Britten S, Soenksen DM. Early (34-56 days from last menstrual period) ultrasonographic measurements in normal pregnancies. Hum Reprod. 1996;11(8):1771-4

26. McLennan AC, Schluter PJ. Construction of modern Australian first trimester ultrasound dating and growth charts. J Med Imaging Radiat Oncol. 2008; 52(5):471-9.

27. Taipale P, Hiilesmaa V. Predicting delivery date by ultrasound and last menstrual period in early gestation. Obstet Gynecol. 2001;97(2):189-94.
28. Mahendru AA, Wilhelm-Benartzi CS, Wilkinson IB, McEniery CM, Johnson S Lees C. Gestational length assignment based on last menstrual period, first trimester crown-rump length, ovulation, and implantation timing. Arch Gynecol Obstet. 2016;294(4):867-76.

29. Tan S, Pektas MK, Arslan H. Sonographic evaluation of the yolk sac. J Ultrasound Med. 2012;31(1):87-95.

30. Tan S, Pektai MK, Özcan Al, Akçay Y, Ozat M, Arslan H. Frequency of a persistent yolk sac and its relationship with the gestational outcome. J Ultrasound Med. 2012;31(5):697-702.

31. Cavoretto P, Farina A, Gaeta G, Sigismondi C, Spinillo S, Casiero D, et al. Longitudinal cohort study of uterine artery Doppler in singleton pregnancies obtained by IVF/ICSI with fresh or frozen blastocyst transfers in relation to pregnancy outcomes. Ultrasound Obstet Gynecol. 2020. https:// doi.org/10.1002/uog.21969. Online ahead of print.

32. Maheshwari A, Pandey S, Raja EA, Shetty A, Hamilton M, Bhattacharya S. Is frozen embryo transfer better for mothers and babies? Can cumulative meta-analysis provide a definitive answer? Hum Reprod Update. 2018;24(1): 35-58.

33. Cavoretto $P$, Giorgione $V$, Cipriani $S$, Viganò $P$, Candiani $M$, Inversetti $A$, et al. Nuchal translucency measurement, free $\beta-h C G$ and PAPP-A concentrations in IVF/ICSI pregnancies: systematic review and meta-analysis. Prenat Diagn. 2017; 37(6):540-55.

34. Cavoretto P, Candiani M, Giorgione V, Inversetti A, Abu-Saba MM, Tiberio F, et al. Risk of spontaneous preterm birth in singleton pregnancies conceived after IVF/ICSI treatment: meta-analysis of cohort studies. Ultrasound Obstet Gynecol. 2018;51(1):43-53.

35. Pandey S, Shetty A, Hamilton M, Bhattacharya S, Maheshwari A. Obstetric and perinatal outcomes in singleton pregnancies resulting from ivf/icsi: a systematic review and meta-analysis. Hum Reprod Update. 2012;18(5):485503.

\section{Publisher's Note}

Springer Nature remains neutral with regard to jurisdictional claims in published maps and institutional affiliations.

Ready to submit your research? Choose BMC and benefit from:

- fast, convenient online submission

- thorough peer review by experienced researchers in your field

- rapid publication on acceptance

- support for research data, including large and complex data types

- gold Open Access which fosters wider collaboration and increased citations

- maximum visibility for your research: over $100 \mathrm{M}$ website views per year

At $\mathrm{BMC}$, research is always in progress.

Learn more biomedcentral.com/submissions 